\title{
Clinical significance of molecular genetic changes in sporadic invasive pituitary adenomas
}

\author{
Do-Hyun Nam ${ }^{1}$, Sang-Yong Song', \\ Kyoungsook Park ${ }^{3}$, Mi Hyun Kim ${ }^{1}$, \\ Yeon-Lim Suh², Jung-II Lee ${ }^{1}$, Jong-Soo Kim', \\ Seung-Chyul Hong ${ }^{1}$, Hyung-Jin Shin ${ }^{1}$, \\ Kwan Park', Whan Eoh ${ }^{1}$ and Jong Hyun Kim ${ }^{1,4}$ \\ ${ }^{1}$ Departments of Neurosurgery \\ ${ }^{2}$ Diagnostic Pathology \\ ${ }^{3}$ Samsung Medical Center and Center for Clinical Research, \\ Sungkyunkwan University School of Medicine, Molecular Therapy \\ Research Center, Sungkyunkwan University, Seoul, Korea \\ ${ }^{4}$ Corresponding author: Tel, +82-2-3410-3499 (3490); \\ Fax, +82-2-3410-0048; E-mail, kimjh@smc.samsung.co.kr
}

Accepted 20 August, 2001

Abbreviations: RB, retinoblastoma gene; MEN1, multiple endocrine neoplasm type 1; LOH, loss of heterozygosity; PKC, protein kinase C; PTTG, pituitary tumor transforming gene; PRL, prolactin; ACTH, adrenocorticotropic hormone; TSH, thyroid stimulating hormone; $\mathrm{FSH}$, follicle stimulating hormone; LH, luteinizing hormone; SSCP, single-strand conformation polymorphism

\begin{abstract}
Abstact
Several molecular and genetic changes have been found in pituitary adenomas. We looked for correlations between these changes and the degree of invasiveness of the tumors. The invasiveness of 11 pituitary adenomas was graded by Hardy classification. We examined the retinoblastoma gene (RB1.20 on chromosome 13q) and the region around the MEN1 locus (chromosome 11q13.1-5) for loss of heterozygosity. Also examined are p53 mutations using single strain conformation polymorphism, p53 protein overexpression using immuno cytochemistry, homozygous deletions of p15 and p16 by polymerase chain reaction, and cellular proliferative activity using MIB-1 antibody. Six tumors (54.5\%) had an LOH at either RB1.20 or the MEN1 locus. LOHs were found more frequently in Grade 4 and stage $E$ tumors (72\% and $67 \%$ ) than in Grade 3 and stage D tumors (25\% and $40 \%)$. However, no mutation or overexpression of p53 was found. No homozygous deletions of p15 or p16 were identified. The cell proliferative index ranged from 0 to $3 \%$. LOH at $11 q 13$ and $13 q$ may be valuable in predicting the invasiveness of pituitary adenomas.
\end{abstract}

Keywords: retinoblastoma, p53, multiple endocrine neoplasm type 1 , invasive pituitary adenoma

\section{Introduction}

Numerous studies have searched for biologically relevant and clinically informative changes to distinguish aggressive pituitary tumors from those with less aggressive growth (Pei et al., 1995; Bates et al., 1997; Rieger et al., 1998; Shimon et al., 1998; Mastronardi et al., 1999). However, there is no concrete dividing line between noninvasive and invasive types of sporadic pituitary adenomas (Kovacs et al., 1996; Blevins et al., 1998). Pituitary adenomas are nearly always monoclonal, and initiated by intrinsic defects, rather than by induction from hypothalamic hormones. Oncogenes and tumor suppressor genes may play a role in pituitary tumorigenesis. Among the oncogenes, mutations of the gsp gene are frequent, but only in somatotropinomas. Mutations in $\mathrm{H}$-ras genes and protein kinase $\mathrm{C}$ (PKC) have been detected in aggressive pituitary adenomas, but the incidence is rare (Thakker et al., 1993; Boggild et al., 1998). The pituitary tumor transforming gene (PTTG), which was recently cloned, may be a molecular marker of invasiveness in hormone-secreting pituitary tumors (Zhang et al., 1999). However, none of these factors provide an accurate prediction of the invasiveness of pituitary adenomas.

Genetic changes in several tumor suppressor genes and cell proliferative activity are known to be associated with invasive sporadic pituitary adenomas. The proposed genetic changes include deletions around the retinoblastoma gene (RB1) at 13q14 and around the multiple endocrine neoplasm type 1 (MEN1) locus at chromosome 11q13. The overexpression of p53 has also been linked to pituitary adenoma (Boggid et al., 1994; Levy et al., 1994; Pei et al., 1995; Thapar et al., 1996; Woloschak et al., 1996; Batas et al., 1997; Ikeda et al., 1997). However, the clinical significance of these changes has not yet been clarified. Pei et al. detected $\mathrm{LOH}$ in markers surrounding the RB gene in 13 of 13 malignant or highly invasive pituitary tumor cases, and suggested that this LOH might have predictive value (Pei et al., 1995). However, Pearce et al. detected LOH of the RB gene in only 2 among 43 pituitary adenomas (Pearce et al., 1996) and Zhu et al. could not detect LOH in any of 34 pituitary adenomas (Zhu et al., 1994). Although many investigators have studied alterations of the MEN1 gene in sporadic pituitary adenomas, no germ line mutations 
or inactivations were found except for patients with multiple endocrine neoplasia (MEN) type 1 (Daniely et al., 1998; Prezant et al., 1998; Wenbin et al., 1999). Mutations in the p53 gene occur in pituitary adenomas, but they are rare events (Levy et al., 1994). The overexpression of p53 protein, as measured by immunohistochemistry, was detected in $15.2 \%$ of invasive adenomas, but the clinical relevance is not clear (Thapar et al., 1996). Pituitary tumors often develop in knockout mice that lack p27, RB1, or p53. However, lkeda et al. found no p21 or p27 gene abnormalities in 28 pituitary adenomas (Ikeda et al., 1997).

In this study, we evaluated LOH at the RB1.20 and MEN1 loci, mutation and overexpression of the p53 gene, deletion of the $\mathrm{p} 15^{\mathrm{INK} 4 \mathrm{~B} / \mathrm{MTS} 2}(\mathrm{p} 15)$ and $\mathrm{p} 16^{\mathrm{INK} 4 \mathrm{~A} / \mathrm{MTS} 1}(\mathrm{p} 16)$ genes, and cell proliferative index in 11 sporadic pituitary adenomas. These data were compared to the invasiveness of the tumors. $\mathrm{LOH}$ at $11 \mathrm{q} 13$ or $13 q$ could be a clinically relevant predictor of invasiveness.

\section{Materials and Methods}

\section{Patients and specimens}

We obtained 11 surgically resected sporadic invasive pituitary macroadenomas. These samples were derived from 8 men and 3 women with a median age of 51 years (range: 31-81). For pathological examination, samples were fixed in formalin, embedded in paraffin, and sectioned routinely. For molecular studies, samples were immediately frozen at $-80^{\circ} \mathrm{C}$, and genomic DNA was isolated with a standard phenol-chloroform extraction technique (Sambrook et al., 1989). Genomic DNA extracted from peripheral blood leukocytes of each patient was used as a control DNA. Invasive tumors were defined on the basis of magnetic resonance imaging and were classified by Hardy's classification of the degree of invasion (Hardy et al., 1995).

\section{$\mathrm{LOH}$ at RB1.20}

$\mathrm{LOH}$ of the RB gene was analyzed using a highly polymorphic microsatellite marker near the $3^{\prime}$ end of exon 20 (RB1.20). This marker is heterozygous in 94\% of unrelated individuals. Unstained $5 \mu \mathrm{m}$-thick tissue sections on glass slides were deparaffinized, stained with hematoxylin, and then soaked with 30\% TE-glycerol buffer. Histological fields of pituitary adenoma were selected and microdissected under the light microscope using a 30G needle. The dissected cells were immediately suspended in $10 \mu \mathrm{l}$ buffer containing Tris- $\mathrm{HCl}, \mathrm{pH}$ 8.0, $0.1 \mathrm{~mol} / \mathrm{L}$ ethylenediamine tetraacetic acid (EDTA), $\mathrm{pH} 8.0,1 \%$ Tween 20 , and $0.1 \mathrm{mg} / \mathrm{ml}$ proteinase $\mathrm{K}$. The mixture was incubated overnight at $37^{\circ} \mathrm{C}$ and then boiled for $10 \mathrm{~min}$ to inactivate the proteinase $\mathrm{K}$. Ten percent of the solution was used for PCR amplification. The primers used were 5'-TGTATCGGCTAGCCTATCTCA3' and 5'-AATGTAACAAGGTGTGGTGGT-3'. PCR was performed with $20 \mathrm{pmol}$ of each primer, $1.25 \mathrm{mM}$ $\mathrm{MgC12}, 0.2 \mathrm{mM}$ each dNTP, $10 \mathrm{mM}$ Tris (pH 8.3), 50 $\mathrm{mM} \mathrm{KCl}$, and 2.5 units Taq polymerase (Perkin Elmer Cetus, Norwalk, CT) in a total volume of $50 \mu$ l. DNA was amplified by 35 cycles of $94^{\circ} \mathrm{C}$ for $1 \mathrm{~min}, 55^{\circ} \mathrm{C}$ for $1 \mathrm{~min}$, and $72^{\circ} \mathrm{C}$ for $1 \mathrm{~min}$. A $10 \mathrm{~min}$ extension at $72^{\circ} \mathrm{C}$ was done after the last cycle. Electrophoresis was performed with $5 \mu \mathrm{l}$ of PCR products on a $6 \%$ TBE urea polyacrylamide gel (Novex) at $180 \mathrm{~V}$ for $80 \mathrm{~min}$. DNA bands were visualized by silver staining according to the manufacturer's protocol (Bio-Rad, Hercules, CA). The predicted RB 1.20 product was $400-500$ bp in size. PCR products from tumor and genomic DNA were run side by side (Bio-Rad). For informative cases, the absence or significant reduction in the signal of 1 allele relative to the other in the tumor sample was scored as $\mathrm{LOH}$. Results were independently scored by 3 observers with no information about the tumor grade. An $\mathrm{LOH}$ was recorded only if the reduction in intensity was clear and agreed upon by all 3 observers.

\section{LOH around the MEN1 locus}

$\mathrm{LOH}$ at chromosome 11q13 was examined with 4 microsatellite markers (SMSW3, PYGM, INT2, D11s533). Genomic DNA was isolated from fresh frozen pituitary adenomas and leukocytes. The PCR amplification of dinucleotide repeat elements was performed, using 50 ng of genomic DNA as a template and the primers listed in Table 1. One member of each primer pair was $5^{\prime}$ end-

Table 1. Primer sets for polymerase chain reaction on chromosome 11q13.1 5

\begin{tabular}{lllc}
\hline Marker & & \multicolumn{1}{c}{ Primer pairs } & $\begin{array}{c}\% \\
\text { heterozygosity }\end{array}$ \\
\hline SMSW3 & $11 q 13.1$ & 5'-TCAGTAATTAGCCAGACTCTAGG & $89 \%$ \\
PYGM & $11 q 13.1$ & 3'-GGTTTTGAGCTTAAGGAGG & $89 \%$ \\
INT2 & $11 q 13$ & 5'-CTAGCAGAGTCCACCTGCTG & $85 \%$ \\
& & 3'-CCAGCTCCCTAAGTACAGCAC & \\
D11s533 & $11 q 13.5$ & 5'-TTCTGGGTGTGTCTGAAT & $89 \%$ \\
& & 3'-ACACAGTTGCTCTAAAGGGT & \\
\hline
\end{tabular}


labeled with $\left[\gamma^{32} \mathrm{P}\right]$ ATP according to the protocol supplied with T4 kinase (Promega). The PCR reaction was processed through 30 cycles of 1 minute at $94^{\circ} \mathrm{C}$, $60^{\circ} \mathrm{C}$ for $1 \mathrm{~min}$, and $72^{\circ} \mathrm{C}$ for $1 \mathrm{~min}$. The PCR products were denatured and separated on $6 \%$ polyacrylamide gels containing $7 \mathrm{M}$ urea. PCR products from tumor and genomic DNA were run side by side (Bio-Rad). For informative cases, an absence or significant reduction in the autoradiographic signal of one allele relative to the other in the tumor samples was scored as $\mathrm{LOH}$.

\section{Immunohistochemical studies}

Immunohistochemical examination of formalin-fixed, paraffin embedded tissue was performed using the streptavidin-biotin peroxidase method. Serial sections of $5 \mu \mathrm{m}$ thickness were immunostained with anti-growth hormone (1: 700; DAKO Corp., Carpinteria, CA), anti-prolactin (PRL) (1 : 400; DAKO), anti-adrenocorticotropic hormone (ACTH) (1: 700; DAKO), anti-thyroid stimulating hormone (TSH) (1: 80; Biogenex, San Ramon, CA), anti-follicle stimulating hormone $(\mathrm{FSH})(1: 80$; Biogenex), anti-luetinizing hormone (LH) (1: 80; Biogenex), MIB-1 (1:100; DAKO), and anti-p53 (1: 80; mixed type, Zymed Laboratories, San Francisco, CA). Immunostained sections were evaluated by an investigator who was blinded to the immunotype and invasion status of the tumor. By counting the number of positively stained cytoplasms or nuclei in 20 high-power fields of each section, we determined a p53 labeling index, proliferative index, and immunopositivity to cellular hormonal secretions.

\section{SSCP of p15, p16, and p53}

We looked for mutations in the p53 gene, and homozygous deletions of the p15 and p16 genes (Kim et al., 1998). Genomic DNA was isolated from fresh frozen pituitary adenomas using phenol-chloroform extraction. To detect homozygous deletions of p15 and p16, we performed PCR co-amplification of p15 exon 2 with GAPDH, and of $\mathrm{p} 16$ exon 2 with GAPDH (primers listed in Table 2). Products were electrophoresed on a $1.5 \%$ agarose gel. To examine mutations in p53, genomic DNA was PCR amplified with p53 gene-specific primer sets (exons 5-8 primer sets, Table 2). After PCR, samples were denatured by adding gel loading buffer (95\% formamide, $10-\mathrm{mmol} / \mathrm{L}$ sodium hydroxide, and $0.05 \%$ xylene cyanol FF) and heating at $94^{\circ} \mathrm{C}$ for $2 \mathrm{~min}$. Electrophoresis was performed on a precast gradient polyacrylamide gel (4-20\%; Novex) at $300 \mathrm{~V}, 5^{\circ} \mathrm{C}$ for $6 \mathrm{~h}$. The DNA bands were visualized by silver staining following the manufacturers protocol (Bio-Rad).

Table 2. Primer pairs for amplification for p53 exons and p15 and p16 exons

\begin{tabular}{ll}
\hline Targets & PCR primers \\
\hline p15 exon 2 & 5'-TGGTATCGTGGAAGGACTCATGAC-3' \\
& 5'-AGCGAATTCGGGTGGGAAATTGGGTAA- \\
& GAA-3' \\
p16 exon 2 & 5'-TCTGACCATTCTGTTCTCTC-3' \\
& 5'-CTCAGCTTTGGAAGCTCTCA-3' \\
GADPH & 5'-TGGTATCGTGGAAGGACTCATGAC-3' \\
& 5'-ATGCCAGTGAGCTTCCCGTTCAGC-3' \\
p53 exon 5 & 5'-TGTTTGTTTCTTGCTGCCGTGT-3' \\
& 5'-CCCTGTCGTCTCTCCAGCCC-3' \\
p53 exon 6 & 5'-GGGGCTGGAGAGACGACAGG-3' \\
& 5'-AACCACCCTTAACCCCTCCT-3' \\
p53 exon 7 & 5'-CTCATCTTGGGCCTGTGTT-3' \\
& 5'-GGGTCAGCGGCAAGCAGAG-3' \\
p53 exon 8 & 5'-CTGCCTCTTGCTTCTCTTTT-3' \\
& 5'-GAGGCAAGGAAAGGTGATAA-3' \\
\hline
\end{tabular}

Table 3. Demographic data of 11 patients with invasive pituitary macroadenomas. LOH; loss of heterozygosity; IHC: immunohistochemistry; GH: growth hormone, PRL: prolactin; ACTH: adrenocorticotropic hormone; FSH: thyroid stimulating hormone; LH: luteinizing hormone; FSH: follicle stimulating hormone; MIB: MIB-1 proliferative index; p53: p53 labeling index

\begin{tabular}{|c|c|c|c|c|c|c|c|c|c|c|c|c|c|c|c|}
\hline & \multirow{2}{*}{$\begin{array}{l}\text { Sex/ } \\
\text { Age }\end{array}$} & \multicolumn{2}{|c|}{ Hardy Class } & \multirow[t]{2}{*}{ RB1.20 LOH } & \multicolumn{4}{|c|}{ 11q13.1 5 LOH } & \multicolumn{5}{|c|}{$\mathrm{IHC}$ for hormones } & \multicolumn{2}{|c|}{$\mathrm{IHC}$} \\
\hline & & Grade & Stage & & SMSW3 & D1 & INT2 & PYGM & $\mathrm{GH}$ & PRL & ACTH & $\mathrm{FSH}$ & $\mathrm{LH}$ & MIB & P53 \\
\hline 1 & $\mathrm{~m} / 50$ & 3 & $\mathrm{D}$ & - & - & - & - & - & - & - & - & - & - & 0 & 0 \\
\hline 2 & $\mathrm{~m} / 53$ & 3 & D & Y & - & - & - & - & - & - & Y & Y & $\mathrm{Y}$ & & 0 \\
\hline 3 & $\mathrm{f} / 43$ & 4 & E & - & - & $\mathrm{Y}$ & Y & Y & - & - & Y & - & - & 0 & 0 \\
\hline 4 & $f / 44$ & 4 & D & Y & - & - & - & - & Y & Y & Y & Y & $\mathrm{Y}$ & 0 & 0 \\
\hline 5 & $\mathrm{~m} / 81$ & 4 & $E$ & - & - & - & - & - & - & - & - & Y & - & 1 & 0 \\
\hline 6 & $\mathrm{~m} / 35$ & 3 & D & - & - & - & - & - & - & - & - & Y & - & 1.3 & 0 \\
\hline 7 & $\mathrm{~m} / 42$ & 4 & $E$ & Y & - & - & - & - & - & - & Y & Y & - & 0 & 0 \\
\hline 8 & $\mathrm{~m} / 31$ & 3 & $E$ & - & - & - & - & - & - & - & - & Y & - & 0 & 0 \\
\hline 9 & $\mathrm{~m} / 58$ & 4 & E & Y & ND & - & - & - & $Y$ & Y & - & - & - & & 0 \\
\hline 10 & $\mathrm{~m} / 52$ & 4 & $E$ & Y & - & - & - & - & Y & Y & - & Y & - & 3 & 0 \\
\hline 11 & $\mathrm{f} / 73$ & 4 & D & - & - & - & - & - & - & - & - & Y & - & & 0 \\
\hline
\end{tabular}




\section{Results}

\section{Clinical and radiological findings}

All 11 cases showed radiologically cavernous sinus invasion, sellar destruction, or suprasellar extension. Among them, 3 cases showed invasion into the cavernous sinus beyond the lateral margin of cavernous sinus carotid artery; these patients could not undergo radical resection and received postoperative radiotherapy. Sella turcica was destroyed totally (Hardy grade 4: G4) in 7 cases and partially (G3) in 4 cases. Suprasellar and parasellar extension including cavernous sinus was detected in 6 cases (Hardy Stage E: Stage E), while 5 cases did not show cavernous sinus invasion (Stage D) (Table 3).

\section{LOH and invasiveness of pituitary macroadenoma}

Five out of 11 invasive macropituitary adenomas had evidence of $\mathrm{LOH}$ involving the RB1.20 microsatellite. One patient had LOH at the PYGM, INT2, and D11s533 loci. The overall frequency of $\mathrm{LOH}$ in all cases was $54.5 \%$ (6 of 11 ; Figure 1 ). The majority of $\mathrm{LOH}$ was detected at RB1.20. The 3 cases with cavernous sinus invasion beyond the lateral border of cavernous sinus carotid artery revealed LOH involving the RB1.20 microsatellite. Furthermore, the frequency of $\mathrm{LOH}$ increased as the degree of invasion (grades 3 vs 4 , Stage D vs E) increased: 1 patient out of 4 with a G3 tumor showed $\mathrm{LOH}(25 \%)$, whereas 5 out of 7 patients with G4 exhibited the $\mathrm{LOH}(72 \%)$. The frequency of $\mathrm{LOH}$ in stage D tumors was $40 \%$ (2 of 5 ), but it was $67 \%$ (4 of 6 ) for tumors classified as stage $\mathrm{E}$ (Table 3 ).

\section{p53 mutation, p15 and p16 deletion, and immuno- histochemistry}

We found no p53 mutations, or homozygous deletions of p15 or p16 in any cases examined (data not shown). The immunostaining results for p53 protein were all negative. The cell proliferative activity was evaluated in 8 out of 11 specimens by determining the MIB-1 labeling index (LI). Among them, the $\mathrm{LI}$ was $0 \%$ in 5 patients and $3 \%$ or less in 3 patients (Table 3 ). In immunohistochemical studies, we found cells positive for growth hormone in 3 tumors, prolactin in $3, \mathrm{ACTH}$ in $4, \mathrm{FSH}$ in 8 , and $\mathrm{LH}$ in 2 . However, there is no evidence for any correlation between hormone positivity and the degree of invasion of the tumors (Table 3).

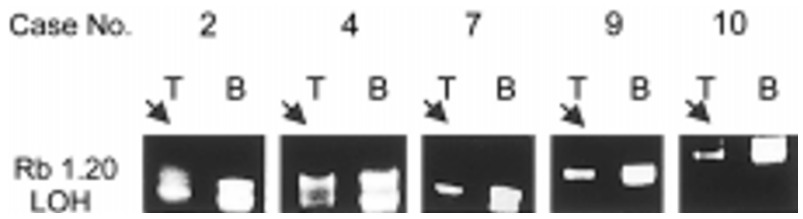

Figure 1. Loss of heterozygosity ( $\mathrm{LOH})$ at the RB1.20. Arrows indicate the presence of $\mathrm{LOH}$. T: tumor tissue DNA; B: blood leukocyte DNA.

\section{Discussion}

Although most pituitary tumors are well-differentiated and histologically benign neoplasms, their clinical behaviors are varied. Invasive pituitary adenomas have a poorer prognosis than noninvasive tumors because they are difficult to remove completely. However, these differences in clinical behavior cannot be discerned from their histopathological appearance. Modern theories of tumorigenesis suggest that the accumulation of independent genetic events is important for tumor initiation and progression. The high incidence of spontaneous pituitary adenoma that develops in heterozygous RB and/or p53-knockout mice (Jacks et al., 1992; Hu et al., 1994; Zhu et al., 1994; Harvey et al., 1995) suggests that the pathways of these proteins are involved in pituitary tumorigenesis. Nonetheless, mutations of the RB gene itself are infrequent in human pituitary adenomas (Cryns et al., 1993; Levy et al., 1994; Pearce et al., 1996). The MEN1 gene was recently cloned and is associated with endocrine tumors of the parathyroid, pancreas, and pituitary (Guru et al., 1997). The incidence of $\mathrm{LOH}$ at $11 \mathrm{q} 13$ in sporadic parathyroid and pancreatic endocrine tumors was $26-38 \%$ and $19-44 \%$, respectively (Pearce et al., 1996). However, in sporadic pituitary adenomas, the incidence was very low, both in this study and another study (Tanaka et al., 1998). Furthermore, there has been no reliable correlation between pituitary tumorigenesis and other tumor suppressor genes, such as p15, p16, p21, and p27 (Woloschak et al., 1996; Ikeda et al., 1997).

Pei et al. detected LOH in all of the 13 malignant or highly invasive pituitary tumors by polymorphic microsatellite markers surrounding the RB gene, but found none in micropituitary adenomas. Pearce et al. detected RB LOH in only 2 cases among 43 pituitary adenomas and Zhu et al. did not detect the LOH in any of 34 pituitary adenomas (Zhu et al., 1994; Pearce et al., 1996). In terms of clinical correlation of $\mathrm{LOH}$ around the RB gene with invasion of pituitary adenomas, Bates et al. demonstrated $\mathrm{LOH}$ at D13S155 (between RB1 and BRCA2 on chromosome 13q12-13) in $25 \%$ of 47 invasive pituitary adenomas (Bates et al., 1997). These reports suggest that $\mathrm{LOH}$ surrounding the RB gene may be partly correlated with the aggressive behavior of pituitary neoplasms. Our results showed an RB LOH in $45 \%$ (5 out of 11 cases) of pituitary adenomas with cavernous sinus invasion. Although there was no statistical significance between degree of invasion and the $\mathrm{Rb} \mathrm{LOH}$ (Table 3), the high frequency of the LOH suggests that it may be associated with the invasiveness in the benign pituitary adenoma. The high frequency of $\mathrm{LOH}$ in our study compared with other previous reports might be ascribed to our use of tumor DNA obtained from homogeneous tumor cells collected by microdissection. These findings suggest that further characteri- 
zation of the role of genetic events at the RB gene and on chromosome 13 may provide clues to the invasiveness of pituitary adenomas. A large prospective study will be required, and must include patients with noninvasive pituitary adenomas. Nevertheless, our assessment of $\mathrm{LOH}$ on the RB gene suggests that this locus will provide useful information about potential tumor behavior. This information cannot be obtained from routine histological methods. Furthermore, detection of the RB LOH is technically simple and therefore feasible as a clinical screening method.

Deletions at 11q13 have been identified in both MEN1related and sporadic parathyroid tumors. In studies of sporadic pituitary adenomas, allelic deletions involving chromosome 11 were analyzed, but LOH was not frequent (Thakker et al., 1993; Prezant et al., 1998; Tanaka et al., 1998). Furthermore, mutations or aberrant expression of the MEN1 gene were rare (Prezant et al., 1998; Wenbin et al., 1999). On the basis of these reports, the MEN1 gene may not play a prominent role in the pathogenesis of sporadic pituitary adenomas. However, no one has analyzed the relationship between MEN1 deletions and invasiveness of pituitary adenomas. In addition to $\mathrm{LOH}$ on chromosome $13 \mathrm{q}$ in pituitary adenoma, Bates et al. detected more frequent $\mathrm{LOH}$ on 11 q13 and 10q26 in 42 noninvasive and 47 invasive pituitary adenomas. The LOH on $11 \mathrm{q} 13$ was $30 \%$ (14/ 47) which was the most frequent event among the invasive tumors (Hardy grade $3 \& 4$ ). The overall frequency of $\mathrm{LOH}$ in the invasive pituitary adenomas was $43 \%$ and even higher among tumors of Hardy grade 4 (73\%), while it was much lower in the noninvasive cases (9.5\%). Our results on LOH at RB1.20 and 11q13 were $52 \%$ among all invasive tumors and $72 \%$ among Hardy grade 4 tumors, which is similar to the previous report. However, the frequency of $11 q 13 \mathrm{LOH}$ was much less frequent in our studies $(9 \%)$ compared with that in the report of Bates et al. (30\%). Although the MEN1 gene may not be pivotal in pituitary tumorigenesis it is quite possible that it is involved in the progression of the disease. Thapar et al. found that p53 expression and proliferative index were useful markers for biologically aggressive behavior of pituitary adenomas (Thapar et al., 1996a; Thapar et al., 1996b; Blevins et al., 1998). Several other reports have revealed a correlation between proliferative index with the invasiveness or recurrence of pituitary adenomas (Daita et al., 1996; Mastronardi et al., 1999). For example, a study of the expression of Ki-67 in 103 pituitary adenomas by Mastronardi et al. showed that the labeling index increased with the invasiveness of pituitary adenomas (3.5\% for invasive adenomas and 5\% for cavernous sinus infiltrating adenomas) (Mastronardi et al., 1999). In our study, a relationship between MIB-1 index and the invasiveness of pituitary adenomas was not evident, probably due to the small number of patients. However,
2 out of 3 patients with MIB-1 expression over $1 \%$ had invasive pituitary adenoma with stage $\mathrm{E}$ and Grade 4. The expression of p53 in invasive pituitary adenoma, however, needs further investigation because of the discrepancies between other reports and our results (Levy et al., 1994; Thapar et al., 1996b). In contrast to the homozygous or heterozygous loss of p16 and p15 genes that is observed in malignant invasive glioma (Schmidt et al., 1994; Izumoto et al., 1995; Walker et al., 1995), alteration in p15 and p16 DNA or those proteins have been found in very rare pituitary adenomas (Woloschak et al., 1996; Seemann et al., 2001). Our results reveal no deletion of the p15 and p16 genes, which are consistent with the previous reports. Studies have also found no association between p21 and p27 with pituitary adenoma (Ikeda et al., 1997). Thus, cell cycle regulatory tumor suppressor genes, including p15, $\mathrm{p} 16$, and p53, may have little significance in the pathogenesis or progression to invasion of pituitary adenomas.

So far, there has been no evidence that pituitary adenomas have MEN1 and RB gene mutations or functional inactivation. These genes may or may not be directly associated with the development or progression of these tumors. However, assessment of the clinical value of the proliferative index and $\mathrm{LOH}$ at these loci may provide important clues to predict the invasiveness of pituitary adenomas. These indicators may be useful in decisions about postsurgical treatment of pituitary adenomas.

\section{Acknowledgement}

This work was supported by Samsung Biomedical Research Institute (grant \#SBRI cc-99-071-1) and Sungkyunkwan University School of Medicine.

\section{References}

Bates AS, Farrell WE, Bicknell EJ, McNicol AM, Talbot AJ, Broome JC, Perrett CW, Thakker RV, Clayton RN. Allelic deletion in pituitary adenomas reflects aggressive biological activaty and has potential value as a prognostic marker. J Clin Endocrinol Metab 1997;82:818-24

Blevins LS Jr, Verity DK, Allen G. Aggressive pituitary tumors. Oncology 1998;12:1307-12

Boggild MD, Jenkinson S, Pistorello M, Boscaro M, Scanarini M, Mc Ternan P, Perrett CW, Thakker RV, Clayton RN. Molecular genetic studies of sporadic pituitary tumors. J Clin Endocrinol Metab 1994;78:387-92

Cryns VL, Alexander JM, Klibanski A, Arnold A. The retinoblastoma gene in human pituitary tumors. J Clin Endocrinol Metab 1993;77:644-46

Daita G, Yonemasu Y. Dural invasion and proliferative potential of pituitary adenomas. Neurol Med Chir 1996;36:211-14

Daniely M, Aviram A, Adams EF, Buchfelde M, Barkai G, Fahlbusch R, Goldman B, Friedman E. Comparative genomic 
hybridization analysis of nonfunctioning pituitary tumors. J Clin Endocrinol Metab 1998;83:1801-5

Guru SC, Olufemi SE, Manickam P, Cumming C, Gieser LM, Pike BL, Bittner ML, Jianf $Y$, Chinaul AC, Nowak NJ, Brzozowska A, Crabtree JS, Wang Y, Roe BA, Weisemann JM, Boguski MS, Agarwal SK, Burns AL, Spiegel AM, Marx SJ, Flejter WL, de Jong PJ, Collins FS, Chandrasekharappa SC. A 2.8-Mb clone contig of the multiple endocrine neoplasia type 1 (MEN1) region at 11q13. Genomics 1997;42: 436-45

Hardy J, Transsphenoidal microsurgical treatment of pituitary tumors. Recent advances in the diagnosis and treatment of pituitary tumors (I. L. J. Ed.), 1979, pp.375-388, Raven Press, New York

Harvey M, Vogel H, Lee E Y, Bradley A, Donehower L A. Mice deficient in both p53 and $\mathrm{Rb}$ develop tumors primarily of endocrine origin. Cancer Res 1995;55:1146-51

Hu M, Gutsmann A, Herbert DC, Bradley A, Lee WH, Lee EY. Heterozygous $\mathrm{Rb}-1$ delta 20/+mice are predisposed to tumors of the pituitary gland with a nearly complete penetrance. Oncogene 1994;9:1021-27

Ikeda $\mathrm{H}$, Yoshimoto T, Shida N. Molecular analysis of p21 and p27 genes in human pituitary adenomas. $\mathrm{Br} \mathrm{J}$ Cancer 1997; 76:1119-23

Izumoto S, Arita N, Ohnishi T, Hiraga S, Taki T, Hayakawa T. Homozygous deletions of $\mathrm{p} 16^{\text {INK4AMTS1 }}$ and $\mathrm{p} 15^{\text {INK4B/MTS2 }}$ genes in glioma cells and primary glioma tissues. Cancer Lett 1995;97:241-47

Jacks T, Fazeli A, Schmitt EM, Bronson RT, Goodell MA, Weinberg RA. Effects of an Rb mutation in the mouse. Nature 1992;359:295-300

Kim JR, Kim SY, Kim MJ, Kim JH. Alterations of CDKN2 (MTS1/p16INK4A) gene in paraffin-embedded tumor tissues of human stomach, lung, cervix and liver cancers. Exp Mol Med 1998; 30:109-14

Kovacs K. Molecular biological research in pituitary adenomas from the pathologists' view. Acta Neurochir Suppl (Wien) 1996;65:4-6

Levy A, Hall L, Yeudall WA, Lightman SL. p53 gene mutations in pituitary adenomas: rare events. Clin Endocrinol (Oxf) 1994; 41:809-14

Mastronardi L, Guiducci A, Spera C, Puzzilli F, Liberati F, Maira G. Ki-67 labelling index and invasiveness among anterior pituitary adenomas: analysis of 103 cases using the MIB-1 monoclonal antibody. J Clin Pathol 1999;52:107-11

Pearce SH, Trump D, Wooding C, Sheppard MN, Clayton RN, Thakker RV. Loss of heterozygosity studies at the retinoblastoma and breast cancer susceptibility (BRCA2) loci in pituitary, parathyroid, pancreatic and carcinoid tumours. Clin Endocrinol (Oxf) 1996;45:195-200

Pei L, Melmed S, Scheithauer B, Kovacs K, Benedict WF, Prager D. Frequent loss of heterozygosity at the retinoblastoma susceptibility gene (RB) locus in aggressive pituitary tumors: evidence for a chromosome 13 tumor suppressor gene other than RB. Cancer Res 1995;55:1613-16

Prezant TR, Levine J, Melmed S. Molecular characterization of the MEN1 tumor suppressor gene in sporadic pituitary tumors. J Clin Endocrinol Metab 1998;83:1388-91

Rieger A, Rainov NG, Ebel H, Sanchin L, Shibib K, Helfrich C, Hoffmann O, Burkert W. Factors predicting pituitary adenoma invasiveness in acromegalic patients. Neurosurg Rev 1997; 20:182-87

Sautner D, Saeger W. Invasiveness of pituitary adenomas. Pathol Res Pract 1991;187:632-36

Schmidt EE, Ichimura K, Reifenberger G, Collins VP. CDKN2 (p16/MTS1) gene deletion or CDK4 amplification occurs in the majority of glioblastomas. Cancer Res 1994;54:6321-24

Seemann N, Kuhn D, Wrocklage C, Keyvani K, Hackl W, Buchfelder M, Fahlbusch R, Paulus W. CDKN2A/p16 inactivation is related to pituitary adenoma type and size. J Pathol 2001;193:491-97

Shimon I, Hinton DR, Weiss MH, Melmed S. Prolactinomas express human heparin-binding secretory transforming gene (hst) protein product: marker of tumour invasiveness. Clin Endocrinol (Oxf) 1998;48:23-29

Tanaka C, Kimura T, Yang P, Moritani M, Yamaoka T, Yamada $\mathrm{S}$, Sano T, Yoshimoto K, Itakura M. Analysis of loss of heterozygosity on chromosome 11 and infrequent inactivation of the MEN1 gene in sporadic pituitary adenomas. J Clin Endocrinol Metab 1998;83:2631-34

Thakker RV, Pook MA, Wooding C, Boscaro M, Scanarini M, Clayton RN. Association of somatotrophinomas with loss of alleles on chromosome 11 and with gsp mutations. J Clin Invest 1993;91:2815-21

Thapar K, Kovacs K, Scheithauer BW, Stefaneanu L, Horvath E, Pernicone PJ, Murray D, Laws ER, Jr. Proliferative activity and invasiveness among pituitary adenomas and carcinomas: an analysis using the MIB-1 antibody. Neurosurgery 1996a; 38:99-107

Thapar K, Scheithauer BW, Kovacs K, Pernicone PJ, Laws ER, Jr. p53 expression in pituitary adenomas and carcinomas: correlation with invasiveness and tumor growth fractions. Neurosurgery 1996b;38:763-71

Walker DG, Duan W, Popovic EA, Kaye AH, Tomlinson FH, Lavin M. Homozygous deletions of the multiple tumor suppressor gene 1 in the progression of human astrocytomas. Cancer Res 1995;55:20-23

Wenbin C, Asai A, Teramoto A, Sanno N, Kirino T. Mutations of the MEN1 tumor suppressor gene in sporadic pituitary tumors. Cancer Lett 1999;142:43-47

Woloschak M, Yu A, Xiao J, Post KD. Frequent loss of the $\mathrm{P} 16^{\text {INK4a }}$ gene product in human pituitary tumors. Cancer Res 1996;56:2493-96

Zhang X, Horwitz GA, Heaney AP, Nakashima M, Prezant TR, Bronstein MD, Melmed S. Pituitary tumor transforming gene (PTTG) expression in pituitary adenomas. J Clin Endocrinol Metab 1999;84:761-67

Zhu J, Leon SP, Beggs AH, Busque L, Gilliland DG, Black PM. Human pituitary adenomas show no loss of heterozygosity at the retinoblastoma gene locus. J Clin Endocrinol Metab 1994; 78:922-27 